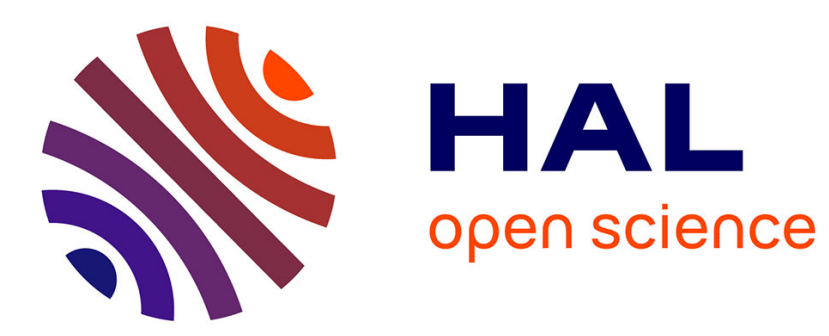

\title{
Hydrogen bonding and delocalization in the ELF analysis approach
}

Bernard Silvi, Henryk Ratajczak

\section{To cite this version:}

Bernard Silvi, Henryk Ratajczak. Hydrogen bonding and delocalization in the ELF analysis approach. Physical Chemistry Chemical Physics, 2016, 18 (39), pp.27442 - 27449. 10.1039/C6CP05400E . hal01383126

\section{HAL Id: hal-01383126 \\ https://hal.sorbonne-universite.fr/hal-01383126}

Submitted on 18 Oct 2016

HAL is a multi-disciplinary open access archive for the deposit and dissemination of scientific research documents, whether they are published or not. The documents may come from teaching and research institutions in France or abroad, or from public or private research centers.
L'archive ouverte pluridisciplinaire HAL, est destinée au dépôt et à la diffusion de documents scientifiques de niveau recherche, publiés ou non, émanant des établissements d'enseignement et de recherche français ou étrangers, des laboratoires publics ou privés. 


\title{
Hydrogen bonding and delocalization in the ELF analysis approach ${ }^{\dagger}$ Bernard Silvi*a and Henryk Ratajczak ${ }^{b}$
}

\author{
Received 3rd August 2016, Accepted Xth XXXXXXXXX 201X \\ First published on the web Xth XXXXXXXXXX 201X \\ DOI: $10.1039 /$ b000000x
}

The delocalization of the electron density in the proton donor fragment has been studied for 21 complexes, $\mathrm{A}-\mathrm{H} \cdots \mathrm{B}$ $\left(\mathrm{A}=\mathrm{F}, \mathrm{Cl} ; \mathrm{B}=\mathrm{Ne}, \mathrm{Ar}, \mathrm{CO}_{2}, \mathrm{~N}_{2}, \mathrm{FH}, \mathrm{ClH}, \mathrm{H}_{2} \mathrm{O}, \mathrm{PH}_{3}, \mathrm{NH}_{3}, \mathrm{Cl}^{-}, \mathrm{F}^{-}\right.$, covering the whole range of hydrogen bond strength. The proton donor and proton acceptor fragments are defined by a minimum variance principle the QTAIM and achieved by the ELF partition schemes. It is shown the variance of the proton donor population as well as the charge transfer between the fragments calculated with the $E L F$ partition are always smaller than the those evaluated within the QTAIM framework. For both partition schemes, the variance and the charge transfer are correlated with the hydrogen bond strength. It is shown that the variance varies as the square root of the value of $E L F$ at the hydrogen bond interaction point (i.e. The saddle point at the boundary of the proton donor and proton acceptor moieties) $\eta_{v v^{\prime}}$ providing a numerical proof of the conjecture that the $E L F$ partition satisfies a minimum variance condition and an explanation of the success of the core valence bifurcation index as indicator of the hydrogen bond strength. The $E L F$ technique has been then applied to the study of hydrogen bonded crystals for which the variance of the fragment population has been estimated from $\eta_{v v^{\prime}}$. The system investigated are $\mathrm{KHF}_{2}, \mathrm{KDP}$ and ice VIII. The results are consistent with very strong hydrogen bonds in the two former crystal and of medium-weak bonding in ice. In ice VIII the variance, and therefore the hydrogen bond strength, increases with pressure yielding a phase transition toward ice $\mathrm{X}$ in which the hydrogen bond is characterized as very strong. Our study emphasizes the importance of the partition scheme which defines the proton donor fragment and of the role of the electron density delocalization between the fragments which is, according to us, often improperly termed as covalence.

\section{Introduction}

Since $1920^{1,2}$ the scientific literature on the hydrogen bond has been growing enormously practically nearly every day due to its importance in the field of inter- and intra-molecular interactions and its role in the creation of structures and properties of molecular systems, e.g. like DNA, and condensed media: liquids e.g. like water ${ }^{3}$ and solids, e.g. like $\mathrm{KDP}^{4}$. Much attention has been paid to understand "the nature of hydrogen bond interaction" ${ }^{4-10}$. Since the hydrogen atom in the hydrogen bridge, $\mathrm{A}-\mathrm{H} \cdots \mathrm{B}$, is located between two electronegative atoms, $(\mathrm{A}, \mathrm{B})$, it was obvious to think that $\mathrm{A}-\mathrm{H}$ bond should be covalent and the $\mathrm{H} \cdots \mathrm{B}$ bond electrostatic in nature. However, in the development of modern quantum chemistry methods to the study of larger electronic systems the "consensus" has been reached that in the hydrogen bond the electrostatic as well as covalent interac-

${ }^{a}$ Address, Sorbonne Universités, UPMC, Univ Paris 06, UMR 7616, Laboratoire de Chimie Théorique, case courrier 137, 4 place Jussieu, F-75005 Paris, France, Fax: 3314427 5526; Tel.: +33 14427 4211; E-mail: silvi@lct.jussieu.fr ${ }^{b}$ Address, Faculty of Chemistry, University of Wroctaw, 14 F. Joliot Curie Str. 50-383 Wroctaw, Poland, E-mail: henryk.ratajczak@gmail.com tions are important; however, their relative contributions depends strongly upon the energy interaction (or bond distance between $\mathrm{A}$ and $\mathrm{B}$ atoms). In weak hydrogen bonded complexes like e.g. $\mathrm{F}-\mathrm{H} \cdots \mathrm{N}_{2}$ electrostatic interaction dominates, but in stronger ones, like $[\mathrm{F} \cdots \mathrm{H} \cdots \mathrm{F}]^{-}$ covalent interaction is relatively large ${ }^{4}$.

Very recently an interesting discussion on the nature of molecular interactions (including the hydrogen bond) has been carried out by Frank Weinhold and Roger A. Klein ${ }^{11}$ emphasizing its essential quantum nature.

However, so far most information on the "nature" of the hydrogen bond and its structure and properties we have got from the quantum chemical calculations carried out on the isolated hydrogen bonded complexes ${ }^{5,9}$. Large literature data on experimental properties of hydrogen bonded systems demonstrate the sensitivity of the hydrogen bridge upon the environment ${ }^{12-16}$.

In 1994 a topological method to study molecular interactions has been developed by Silvi and Savin ${ }^{17}$ in the framework of the Electron Localization Function (ELF) of Becke and Edgecombe ${ }^{18}$. This method which provides a partition of the space into chemically representative regions was successfully applied to study different hydrogen-bonded complexes in the gas phase ${ }^{6,7}$. 
The purpose of the present paper is to investigate the delocalization in hydrogen bonded systems within the ELF partition scheme in order to address the controversial problem of the nature of the hydrogen bonding and particularly of its "covalency". For this purpose 21 molecular complexes three crystals, $\mathrm{KHF}_{2}$, KDP and ice VIII, will be considered.

\section{Hydrogen bonding in the ELF analysis ap- proach}

Covalency of hydrogen bonding sounds like an oxymoron since covalence implies the sharing of an electron pair by the valence shells of two atoms which is not the case in hydrogen bonded complexes. The description of the attractive interaction in terms of electrostatic, induction and dispersion forces is an accepted paradigm for a large majority of hydrogen bonded complexes. However, in a recent article entitled "What is a hydrogen bond? Resonance covalency in the supramolecular domain" 11 Frank Weinhold and Roger A. Klein conclude "Evidencebased regression methods point instead to resonance-type "charge transfer" superposition of competing A-H...: B v.s. $\mathrm{A}:^{-}{ }^{-} \ldots \mathrm{H}-\mathrm{B}+$ bond patterns as the defining characteristic of H-bonding, whereas classical-type (exchange-free) London dispersion and electrostatic "dipole-dipole" forces play only a secondary role. To some extent, this description is consistent with a picture in which the hydrogen bonded complex $\mathrm{A}-\mathrm{H} \cdots: \mathrm{B}$ is considered as being the initial step of a proton transfer reaction yielding $\mathrm{A}:^{-} \ldots \mathrm{H}-$ $\mathrm{B}^{+7}$. The Legon and Millen rules ${ }^{19,20}$ predicting the geometry of hydrogen bonded complex are accounted for by applying the Rice and Teller's least motion principle ${ }^{21}$ to the proton transfer reaction.

The covalency of the hydrogen bond has been the subject of a review article of S. Grabowski ${ }^{5}$ in which different techniques of characterization, mostly interaction energy decomposition and QTAIM, are discussed. In the conclusion Grabowski writes "There is abundant evidence that covalency is attributed to hydrogen bond as a kind of interaction, not only to short and strong interactions. The covalency is the driving force of hydrogen bond determining its characteristics." The delocalization energy is shown to be correlated with the proton acceptor distance as well as with the binding energy. The natural bond orbital (NBO) analysis is another support for the covalent interpretation of hydrogen bonding ${ }^{22}$, Weinhold and Klein define the hydrogen bond as "A fractional chemical bond of coordinative $\mathrm{A}-\mathrm{H} \cdots \mathrm{B}$ Lewis acid-base type, associated with the partial intermolecular $\mathrm{A}-\mathrm{H} \cdots: \mathrm{B} \leftrightarrow \mathrm{A}: . . . \mathrm{HB}$ resonance (3 center/4-electron proton sharing) commonly originating in the $n_{\mathrm{B}} \rightarrow \sigma_{\mathrm{AH}}^{*}$ donor-acceptor interaction between the lone pair $n_{\mathrm{B}}$ of the Lewis base and the hydride antibond $\sigma_{\mathrm{AH}}^{*}$ of the Lewis acid."

2.1 The variance of electron populations: a measure of the delocalization

The delocalization can be quantified either by methods relying on the structure of the approximate wave function such as interaction energy decompositions, NBO analysis, weight of valence bond structure or by a statistical approach carried out on non two overlapping space-filling domains representative of the proton donor $\left(\Omega_{\mathrm{AH}}\right)$ and proton acceptor $\left(\Omega_{\mathrm{B}}\right)$ subsystems. The electron count over these domains is performed with the populations operators $^{23,24} \hat{N}\left(\Omega_{\mathrm{AH}}\right)$ and $\hat{N}\left(\Omega_{\mathrm{B}}\right)$. The sum of these operators is the number of electron of the system, $N=N_{\mathrm{AH}}+N_{\mathrm{B}}$ and their eigenvalues the series of integers $0, \ldots, N$ which represent all the accessible numbers of electrons within each domain. The expectation values of these operators, $\bar{N}_{\mathrm{AH}}$ and $\bar{N}_{\mathrm{B}}$ are evaluated by integrating the one electron density $\rho(\mathbf{r})$ over $\hat{N}\left(\Omega_{\mathrm{AH}}\right)$ and $\hat{N}\left(\Omega_{\mathrm{B}}\right)$ :

$$
\begin{aligned}
\bar{N}_{\mathrm{AH}} & =\int_{\Omega_{\mathrm{AH}}} \rho(\mathbf{r}) d \mathbf{r}=\sum_{i=0}^{N} i P_{i}\left(\Omega_{\mathrm{AH}}\right) \\
\bar{N}_{\mathrm{B}} & =\int_{\Omega_{\mathrm{B}}} \rho(\mathbf{r}) d \mathbf{r}=\sum_{i=0}^{N} i P_{i}\left(\Omega_{\mathrm{B}}\right)
\end{aligned}
$$

where $P_{i}(\Omega)$ is the probability of finding $i$ and only $i$ electrons in the given domain $\Omega$. A measure of the delocalization/localization is provided by the variance of the population $\sigma^{2}\left(N_{\Omega}\right)$ which expresses the spread of the eigenvalues of the electron count operator:

$$
\begin{aligned}
\sigma^{2}\left(N_{\Omega}\right) & =\sum_{i=0}^{N} P_{i}(\Omega)(i-\bar{N}(\Omega))^{2}=\left\langle\hat{N}(\Omega)^{2}-\bar{N}(\Omega)^{2}\right\rangle \\
& =\bar{\Pi}(\Omega, \Omega)-\bar{N}(\Omega)^{2}+\bar{N}(\Omega)
\end{aligned}
$$

in which $\bar{\Pi}(\Omega, \Omega)$ denotes the pair population of the domain $\Omega$ i.e.:

$$
\bar{\Pi}(\Omega, \Omega)=\iint_{\Omega} \pi\left(\mathbf{r}_{1}, \mathbf{r}_{2}\right) d \mathbf{r}_{1} d \mathbf{r}_{2}
$$

where $\pi\left(\mathbf{r}_{1}, \mathbf{r}_{2}\right)$ is the two-electron density distribution. In the context of hydrogen bonded complexes, the net electronic charge transfer from the Lewis base towards the Lewis acid is the difference of the population of the proton donor and of the number of electrons in the corresponding unassociated species:

$$
\text { C.T. }=\bar{N}\left(\Omega_{\mathrm{AH}}\right)-N_{\mathrm{AH}}=N_{\mathrm{B}}-\bar{N}\left(\Omega_{\mathrm{B}}\right) \approx P_{N_{\mathrm{AH}}+1}-P_{N_{\mathrm{AH}}-1}
$$


Moreover,

$$
\begin{aligned}
\sigma^{2}\left(N\left(\Omega_{\mathrm{AH}}\right)\right) & =\sigma^{2}\left(N\left(\Omega_{\mathrm{B}}\right)\right)=-\left\langle\widehat{\operatorname{cov}}\left(\Omega_{\mathrm{AH}}, \Omega_{\mathrm{B}}\right)\right\rangle \\
& \approx P_{N_{\mathrm{AH}}+1}-P_{N_{\mathrm{AH}}-1}
\end{aligned}
$$

where

$$
\left\langle\widehat{\operatorname{cov}}\left(\Omega_{\mathrm{AH}}, \Omega_{\mathrm{B}}\right)\right\rangle=\int_{\Omega_{\mathrm{AH}} \Omega_{\mathrm{B}}} \pi\left(\mathbf{r}_{1}, \mathbf{r}_{2}\right) d \mathbf{r}_{1} d \mathbf{r}_{2}-\bar{N}\left(\Omega_{\mathrm{AH}}\right) \bar{N}\left(\Omega_{\mathrm{B}}\right)
$$

is the covariance of the domain populations. In the general case of a partition in several domains:

$$
\sigma^{2}\left(N\left(\Omega_{i}\right)\right)=-\sum_{j \neq j}\left\langle\widehat{\operatorname{cov}}\left(\Omega_{i}, \Omega_{j}\right)\right\rangle
$$

the covariance provides a measure of the delocalization between the domains $\Omega_{i}$ and $\Omega_{j}$. The LCAO-MO expression of the covariance in terms of molecular orbital overlap integrals over different domains enabled Ángyan et $\mathrm{al}^{25}$ to define "topological covalent bond orders" as twice the opposite of the covariance. Therefore, variance and covariance appear to measure the delocalization but also the covalence in the sense of orbital based analyses.

2.2 Delocalization in molecular hydrogen bonded complexes

Both Quantum Theory of Atoms in Molecules (QTAIM) $^{26}$ and $E L F^{17,27}$ provide partitions of the electron density in terms of non-overlapping, spacefilling domains. Whereas QTAIM relies upon a physical criterion, namely the fulfilment of the local virial theorem $^{28}$, the $E L F$ partition scheme is conjectured to minimize the domain populations variance ${ }^{27,29-31}$.

The delocalization has been investigated with both QTAIM and ELF partitions for 21 hydrogen bonded complexes ranging from very weak to very strong interaction: $\mathrm{A}-\mathrm{H} \cdots \mathrm{B}\left(\mathrm{A}-\mathrm{H}=\mathrm{FH}, \mathrm{ClH}\right.$; $\mathrm{B}=\mathrm{Ne}, \mathrm{Ar}, \mathrm{CO}_{2}, \mathrm{FH}, \mathrm{ClH}$, $\left.\mathrm{H}_{2} \mathrm{O}, \mathrm{PH}_{3}, \mathrm{NH}_{3}, \mathrm{~F}^{-}, \mathrm{Cl}^{-}\right)$. The calculations of the supermolecule wave functions have been carried out with the Gaussian 03 software $^{32}$ at the B3LYP hybrid functional level ${ }^{33,34}$ and with the $6-311++\mathrm{G}(2 \mathrm{df}, 2 \mathrm{pd})$ extended basis set ${ }^{35-37}$. The partitions into proton donor and proton acceptor domains has been performed and with the TopMod package ${ }^{38}$ as well as the calculation of the electron number probabilities ${ }^{39}$, charge transfers and variances.

The results obtained by the ELF partition presented in table 1 clearly show the increase of the variance and to a lesser extent of the charge transfer with the expected strength of the hydrogen bond. For all system the $E L F$ partition yields subsystems closer to the unassociated species than the QTAIM partition. Both variance (as expected) and charge transfer values are smaller with
ELF than with QTAIM although the differences are very small.

The core-valence bifurcation index ${ }^{40}, I_{\mathrm{CVB}}$, is the hydrogen bond indicator of the $E L F$ approach. It is defined as the difference of $\eta_{\mathrm{cv}}$, the lowest value of the $E L F$ for which the $\mathrm{AH}$ core basin is separated from the valence, and $\eta_{\mathrm{vv}^{\prime}}$, the value at the saddle point linking the proton donor to the acceptor domains, called hereafter hydrogen bond interaction point. In practice, it is graphically determined from the $E L F$ profile along the $\mathrm{A}-\mathrm{H} \cdots \mathrm{B}$ interaction line as illustrated in figure 1 for the extreme cases of the $\mathrm{F}-\mathrm{H} \cdots \mathrm{Ne}$ and $\mathrm{F}-\mathrm{H}-\mathrm{F}^{-}$complexes. $I_{\mathrm{CVB}}$ is positive for weak hydrogen bonds and decreases as the hydrogen bond increases. For a given proton donor moiety, almost linear correlations have been found between the core-valence bifurcation indexes and the complexation energies or $\mathrm{AH}$ stretching frequencies ${ }^{40}$ as well as geometrical parameters ${ }^{41}$.
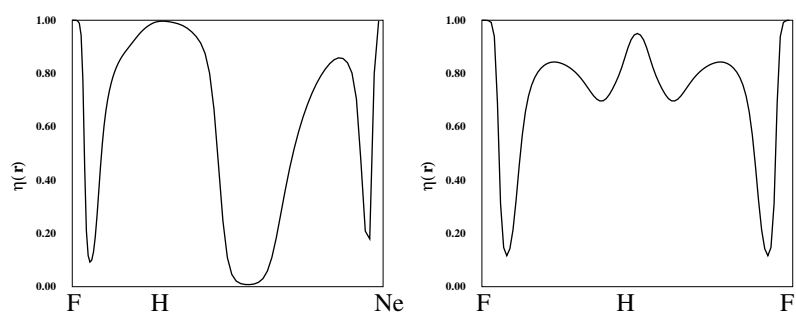

Fig. $1 E L F$ profile along the $\mathrm{A}-\mathrm{H} \cdots \mathrm{B}$ interaction line. Left $\mathrm{F}-\mathrm{H} \cdots \mathrm{Ne}$, right $\mathrm{F}-\mathrm{H} \cdots \mathrm{F}$.

Figure 2 (left) displays the dependence of $I_{\mathrm{CVB}}$ upon the variance of the $\mathrm{AH}$ domain population, $\sigma^{2}\left(\bar{N}\left(\Omega_{\mathrm{AH}}\right)\right)$. A least square fit to a hyperbolic tangent yields:

$$
I_{\mathrm{CVB}} \approx 0.09-11.8 \sigma^{4}
$$

The constant 0.09 corresponds the average of $\eta_{\mathrm{cv}}$ for both $\mathrm{FH}$ and $\mathrm{ClH}$, assuming $\eta_{\mathrm{vv}^{\prime}} \approx 0.09-I_{\mathrm{CVB}}$ the inversion of Eq. 9 yields

$$
\sigma^{2} \approx 0.291 \sqrt{\eta_{\mathrm{vv}^{\prime}}}
$$

Eq. 10 provides rather good estimates of the variance of the proton donor (or proton acceptor) moiety domain populations even for $\mathrm{A} \neq \mathrm{F}, \mathrm{Cl}$ : for the water dimer and the $\mathrm{H}_{5} \mathrm{O}_{2}^{+}$complex cation, the estimated values of the variance are respectively 0.083 and 0.249 against 0.080 and 0.235 calculated. Moreover, eq. 10 provides, at least for the complexes considered here, a numerical proof of the minimal variance conjecture. It is worth noting that the $E L F$ value at bond critical point has been interpreted in terms of delocalzation index ${ }^{42}$. 


\begin{tabular}{|c|c|c|c|c|c|c|c|c|c|c|}
\hline \multirow[b]{2}{*}{ B } & \multicolumn{5}{|c|}{$\mathrm{FH}$} & \multicolumn{5}{|c|}{$\mathrm{ClH}$} \\
\hline & C.T. & $P_{9}$ & $P_{10}$ & $P_{11}$ & $\sigma^{2}$ & C.T. & $P_{9}$ & $P_{10}$ & $P_{11}$ & $\sigma^{2}$ \\
\hline $\mathrm{Ne}$ & $0 \cdot 00$ & $0 \cdot 01$ & 0.98 & $0 \cdot 01$ & $0 \cdot 018$ & $0 \cdot 00$ & $0 \cdot 01$ & 0.98 & $0 \cdot 01$ & 0.017 \\
\hline $\mathrm{Ar}$ & 0.01 & $0 \cdot 01$ & 0.96 & 0.02 & 0.035 & 0.01 & $0 \cdot 01$ & 0.98 & $0 \cdot 01$ & 0.019 \\
\hline $\mathrm{CO}_{2}$ & 0.01 & 0.02 & 0.95 & 0.03 & 0.055 & $0 \cdot 01$ & 0.02 & 0.95 & 0.03 & 0.047 \\
\hline $\mathrm{N}_{2}$ & 0.01 & $0 \cdot 02$ & 0.94 & 0.03 & 0.057 & $0 \cdot 01$ & 0.02 & 0.96 & $0 \cdot 02$ & 0.040 \\
\hline FH & 0.02 & 0.02 & 0.93 & 0.04 & 0.068 & $0 \cdot 01$ & 0.02 & 0.94 & 0.03 & 0.056 \\
\hline $\mathrm{ClH}$ & 0.02 & 0.03 & 0.93 & 0.04 & 0.075 & 0.02 & 0.02 & 0.94 & 0.04 & 0.063 \\
\hline $\mathrm{H}_{2} \mathrm{O}$ & 0.03 & 0.04 & 0.89 & 0.07 & $0 \cdot 112$ & 0.03 & 0.03 & 0.90 & 0.07 & $0 \cdot 105$ \\
\hline $\mathrm{PH}_{3}$ & 0.04 & 0.03 & 0.89 & 0.07 & $0 \cdot 112$ & 0.04 & 0.03 & 0.90 & 0.07 & $0 \cdot 106$ \\
\hline $\mathrm{NH}_{3}$ & 0.05 & 0.04 & 0.86 & $0 \cdot 10$ & $0 \cdot 150$ & $0 \cdot 10$ & 0.04 & 0.83 & $0 \cdot 12$ & $0 \cdot 181$ \\
\hline $\mathrm{Cl}^{-}$ & 0.06 & 0.05 & 0.84 & $0 \cdot 11$ & $0 \cdot 173$ & $0 \cdot 22$ & 0.04 & 0.65 & $0 \cdot 27$ & 0.374 \\
\hline $\mathrm{F}^{-}$ & $0 \cdot 11$ & 0.05 & 0.78 & $0 \cdot 16$ & $0 \cdot 245$ & & & & & \\
\hline
\end{tabular}

Table 1 ELF partition charge transfers (C.T.), electron number probabilities $P_{i}$ and variances of the A-H domains.
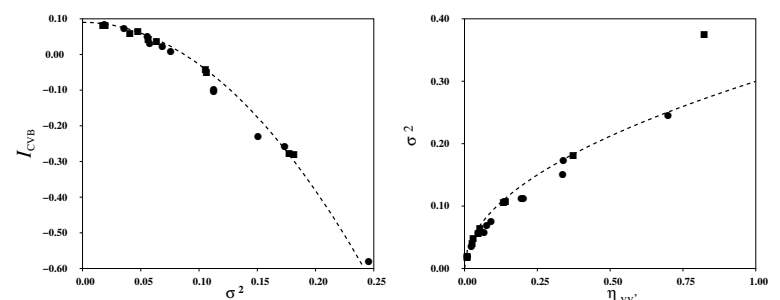

Fig. 2 Left: $I_{\mathrm{CVB}}$ vs. $\sigma^{2}\left(\bar{N}\left(\Omega_{\mathrm{AH}}\right)\right)$. $\left.(-) I_{\mathrm{CVB}} \approx 0.09-11.8 \sigma^{4}\right)$. Right $\sigma^{2}\left(\bar{N}\left(\Omega_{\mathrm{AH}}\right)\right)$ vs. $\eta_{\mathrm{vv}^{\prime}} .(-) \sigma^{2} \approx 0.291 \sqrt{\eta_{\mathrm{vv}^{\prime}}}$. $\mathrm{AH}=$ $\mathrm{FH}, \mathbf{\mathrm { AH }}=\mathrm{ClH}$.

The relation linking variance and covariances, Eq. 8, suggests a generalization of Eq. 10 to systems involving several hydrogen bonds, each characterized by its $\eta_{\mathrm{v}_{\mathrm{i}} \mathrm{v}_{\mathrm{j}}}$, i.e.

$$
\sigma^{2}\left(\bar{N}\left(\Omega_{i}\right)\right) \approx 0.291 \sum_{j \neq i} \sqrt{\eta_{\mathrm{v}_{\mathrm{i}} \mathrm{v}_{\mathrm{j}}}}
$$

In the case of the formic acid dimer, there are two equivalent $\mathrm{O}-\mathrm{H} \cdots \mathrm{O}$ hydrogen bonds with $\eta_{\mathrm{vv}^{\prime}}=0.135$. The calculated and estimated values of the variance of a $\mathrm{HCOOH}$ unit population are respectively 0.234 and 0.229 whereas one finds 0.164 and 0.192 for the hydrogen fluoride cyclic trimer $(\mathrm{FH})_{3}$. One of the main advantages of Eq. 10 is that it provides a reliable estimate of the delocalization/covalence when the exact calculation of the variance is difficult (correlated wave functions, periodic systems) or when the partition in proton donor and acceptor subsystem in not possible (intramolecular hydrogen bond).

A simplified scheme can be proposed for the estima- tion of the delocalization/covalence in hydrogen bonded complexes from the following remarks:

1. The ELF partition provides a lower bound of the variance and therefore of the delocalization,

2. The QTAIM partition yields results very close to ELF ones,

3. An estimate of the variance/covariance can be calculated with the $E L F$ value at the H-bond critical point.

The analysis reduces then to the determination of the $\mathrm{H}$ bond critical point either in ELF or QTAIM frameworks followed by the calculation of the $E L F$ at this point and the estimation of the variance by Eq. 10. This procedure could be even carried out on experimental densities with Tsirelson's formula ${ }^{43}$.

2.3 Delocalization in hydrogen bonded crystalline solids

\subsubsection{Computational Methods}

The Hartree-Fock crystalline wave functions have been calculated with the CRYSTAL98 program ${ }^{44}$. In this method the wave function is approximated by a single determinant of crystalline orbitals expressed in terms of linear combinations of Bloch functions themselves built as an expansion of the atomic basis functions of each unit cell. As input the program requires the crystallographic parameters, the atomic basis set, a set of threshold parameters controlling the truncation of infinite sums and the shrinking factors of the reciprocal space integration. In a second step the $E L F$ function is evaluated over a 
regular grid spanning the conventional cell with the help of the Topond98 program ${ }^{45}$. This grid is afterwards processed in order to identify the localization basins necessary for the graphical representations produced with the Amira 3.0 software ${ }^{46}$.

The structural parameters and the basis sets used in the present calculation are presented in table 2

The available periodic softwares do not enable the calculation of pair functions and therefore of the variances of the populations. However, realistic estimates can be obtained with prototype molecular systems representative of the site of the interaction. For $\mathrm{KHF}_{2}, \mathrm{KDP}$ and ice VIII we have considered the $\mathrm{FHF}^{-}$anion, the $\left(\mathrm{H}_{2} \mathrm{PO}_{4}\right)_{2}^{2-}$ dianion, the water dimer and a water pentamer which were calculated using the B3LYP functional with the 6$311++\mathrm{G}(2 \mathrm{df}, 2 \mathrm{pd})$ basis set.

\subsubsection{Hydrogen bonds in solids: overview}

As previously mentioned a hydrogen bonded complex can be considered as the initial step of the proton transfer reaction

$$
\mathrm{A}-\mathrm{H} \cdots \mathrm{B}->: \mathrm{A}:{ }^{-\cdots} \mathrm{H}-\mathrm{B}^{+}
$$

which is generally not possible without the help of a polar solvent since the $: \mathrm{A}:{ }^{-} \cdot \mathrm{H}-\mathrm{B}^{+}$ionic pair does not correspond to a minimum of the energy hypersurface. The evolution of the bonding along the proton transfer coordinate has been studied by the ELF technique in the cases of internal transfers ${ }^{58}$ or in ionic species ${ }^{59,60}$ showing that the proton transfer is a two-step reaction. The first step occurs before the transition state. It corresponds to the covalent dissociation of the $\mathrm{AH}$ bond: the $\mathrm{V}(\mathrm{A}, \mathrm{H})$ disynaptic basin splits into the $\mathrm{V}(\mathrm{A})$ and $\mathrm{V}(\mathrm{H})$ monosynatic basin. After the transition state, the $\mathrm{V}(\mathrm{H})$ and $\mathrm{V}(\mathrm{B})$ basins merge into $\mathrm{V}(\mathrm{B}, \mathrm{H})$ forming a new covalent bond from the hydrogen atom and the $\mathrm{B}$ atom lone pair.

Figure 3 reproduces the potential energy curves for weak and very strong hydrogen bonds of Emsley's review on the very strong hydrogen bonding ${ }^{61}$. In most periodic systems, the same group of atoms is simultaneously proton donor and proton acceptor and therefore a collective proton transfer leaves the asymmetric unit chemically unchanged, i.e.:

$$
(\mathrm{A}-\mathrm{H} \cdots \mathrm{B}-\mathrm{H} \cdots)_{\mathrm{n}}->(\mathrm{H}-\mathrm{A} \cdots \mathrm{H}-\mathrm{B} \cdots)_{\mathrm{n}}
$$

and therefore, the potential is expected to be either symmetric double-minimum or symmetric single minimum. The proton transfer is only possible for double well potentials whereas single well potentials imply that the proton which cannot be simultaneously located in the $\mathrm{V}(\mathrm{A}, \mathrm{H})$ and $\mathrm{V}(\mathrm{B}, \mathrm{H})$ must be in a $\mathrm{V}(\mathrm{H})$ basin which is the $E L F$ signature of the very strong hydrogen bonding.

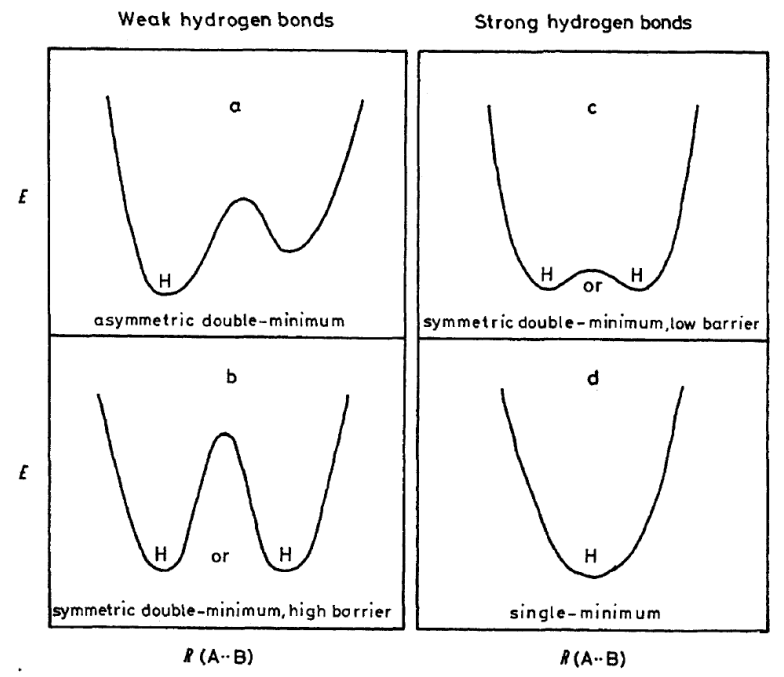

Fig. 3 Potential functions for hydrogen bond and proton transfer. Reproduced from Ref. ${ }^{61}$ with permission from The Royal Society of Chemistry.

\subsection{3 $\mathrm{KHF}_{2}$}

The structure of the $\mathrm{KHF}_{2}$ crystal has been refined by Ibers ${ }^{56}$ who concluded that "that the $\mathrm{F}-\mathrm{H}-\mathrm{F}$ ion in $\mathrm{KHF}_{2}$ is linear and symmetric" ${ }^{56}$, in other words that the potential has to be considered as symmetric. Figure 4 displays the localization domains bounded by the $E L F=0.8$ isosurface in the left part for the $\mathrm{KHF}_{2}$ conventional cell and for the prototype anion $\mathrm{FHF}^{-}$in the right part. In the crystal the potassium cations give rise to large core localization domains represented in magenta whereas the large red volumes represent to the valence shells of the fluorine anion and the small blue volumes surround the protons. The picture of the localization domains of the prototype anion is very similar. The topological analysis of the $E L F$ gradient field in the anion shows two monosynaptic $\mathrm{V}(\mathrm{F})$ basins in the fluorine valence shell, one with its attractor on the $\mathrm{FH}$ axis and the other with a circular attractor in a plane perpendicular to this axis. They surround the fluorine core basins $\mathrm{C}(\mathrm{F})$ not visible in the figure. The monosynaptic $\mathrm{V}(\mathrm{H})$ basin gives rise to the small domains between the two fluorine anions. The population of this basin is small, c. a. $0.24 \mathrm{e}$. The attractive Coulomb potential yields a small electron density around the proton, in fact there is no bare proton in chemistry. The profiles of the $E L F$ function along the FHF line displayed in figure 5 typical of the very strong 


\begin{tabular}{|c|c|c|c|c|}
\hline \multicolumn{5}{|c|}{$F d d 2$} \\
\hline lattice parameters & \multicolumn{4}{|c|}{$a=b=1062.4 \mathrm{pm}, c=715.4 \mathrm{pm}$} \\
\hline atom & $x$ & $y$ & $z$ & basis set \\
\hline K & 0.0 & 0.0 & 0.5 & $86-511 \mathrm{G}^{47,48}$ \\
\hline $\mathrm{P}$ & 0.0 & 0.0 & 0.0 & $85-21 \mathrm{~d} \mathrm{G}^{49}$ \\
\hline $\mathrm{O}$ & 0.367316 & 0.222268 & 0.130156 & $8-411 G^{50}$ \\
\hline $\mathrm{O}$ & 0.527732 & 0.382684 & 0.119844 & \\
\hline $\mathrm{H}$ & 0.439903 & 0.294855 & 0.125490 & $5-11 G^{51}$ \\
\hline $\mathrm{KHF}_{2}$ & \multicolumn{3}{|c|}{$\mathrm{I} 4 / \mathrm{mcm}$} & \\
\hline lattice parameters & \multicolumn{4}{|c|}{$a=b=567 \mathrm{pm}, c=681 \mathrm{pm}$} \\
\hline atom & $x$ & $y$ & $z$ & basis set \\
\hline K & 0.0 & 0.0 & 0.25 & $86-511 G^{47,48}$ \\
\hline $\mathrm{F}$ & 0.142 & 0.642 & 0.0 & $7-311 \mathrm{G}^{52}$ \\
\hline $\mathrm{H}$ & 0.0 & 0.5 & 0.0 & $5-11 G^{51}$ \\
\hline Ice VIII & \multicolumn{4}{|c|}{$I 4_{1} /$ amd } \\
\hline lattice parameters & \multicolumn{4}{|c|}{$a=b=467.44 \mathrm{pm}, c=679.72 \mathrm{pm}$} \\
\hline atom & $x$ & $y$ & $z$ & basis set \\
\hline $\mathrm{O}$ & 0.0 & 0.25 & 108 & $6-31 G^{* 53}$ \\
\hline $\mathrm{H}$ & 0.0 & 0.417 & 0.1437 & $6-31 G^{* 53}$ \\
\hline
\end{tabular}

Table 2 Structural parameters and basis sets used for the periodic calculations. For KDP, the proton ordered $F d d 2$ phase structural parameters have been adapted from those of the experimental proton disordered $I \overline{4} 2 d$ phase ${ }^{54,55}$. The structural parameters of $\mathrm{KHF}_{2}$ are taken from Ibers ${ }^{56}$ whereas those ice VIII correspond to a pressure of $2.7 \mathrm{Gpa}^{57}$.

hydrogen bond. The value of the function at the boundary between the $\mathrm{V}(\mathrm{H})$ and $\mathrm{V}(\mathrm{F})$ basin are very high: 0.64 in the crystal and 0.70 in the anion. The difference between these two value cannot be interpreted because the periodic calculation has been carried out without diffuse basis functions. The variance of the $\mathrm{V}(\mathrm{H})$ basin population of the prototype anion, $\sigma^{2}=0.22$, is close to that of the FH moiety, 0.25. Applying eq. 10 one get 0.23 for the crystal and 0.24 for the anion.
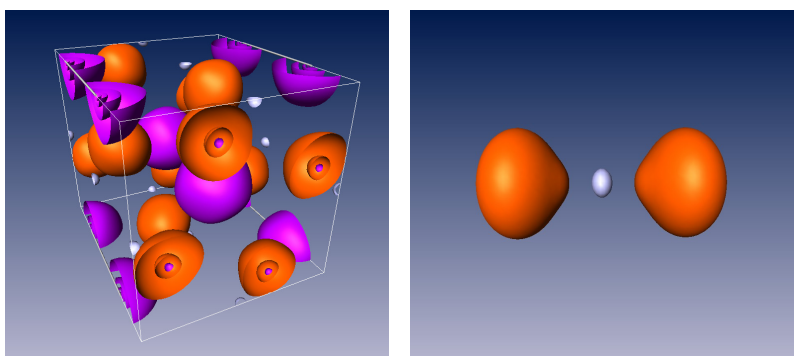

Fig. $4 \mathrm{ELF}=0.8$ localization domains of the $\mathrm{KHF}_{2}$ cell (left) and of the $\mathrm{FHF}^{-}$anion. Color code: magenta $=$core, light blue $=$ protonated valence $(\mathrm{H}$ or $\mathrm{AH})$, redbrick $=$ valence monosynaptic (lone pair), green=disynaptic (bond).
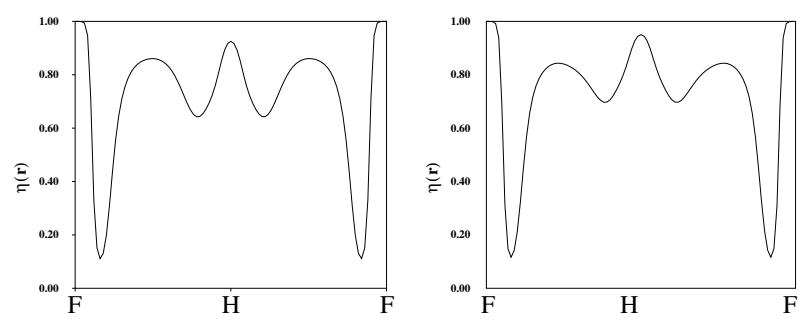

Fig. 5 ELF profiles along the $\mathrm{F}-\mathrm{H} \cdots \mathrm{F}$. Left: $\mathrm{KHF}_{2}$ crystal cell, right: $[\mathrm{FHF}]^{-}$.

\subsubsection{KDP}

The calculated potential of the KDP crystal is symmetric double-minimum with a rather low barrier, i.e. less than $1500 \mathrm{~cm}^{-154}$. According to Emsley ${ }^{61}$ the hydrogen bond should belong to the very strong type. The $E L F=0.8$ localization domains in the KDP crystal are displayed in the left part of figure 6 together with those of the $\left(\mathrm{PO}_{4} \mathrm{H}_{2}\right)_{2}^{2-}$ prototype dianion. The core shell domains of the potassium cation as well as those of the phosphorus and oxygen atoms are represented in magenta, in red are 
the oxygen lone pairs $\mathrm{V}(\mathrm{O})$ domains, in green the disynaptic $\mathrm{P}-\mathrm{O}$ bonds $\mathrm{V}(\mathrm{P}, \mathrm{O})$ domains and in light blue the $\mathrm{V}(\mathrm{H})$ monosynaptic basins. In the $\left[\mathrm{PO}_{4} \mathrm{H}_{2} \cdots \mathrm{PO}_{4} \mathrm{H}_{2}\right]^{2-}$ cluster, the second hydrogen is not involved in a strong hydrogen bond and therefore the large blue domain correspond to the $\mathrm{V}(\mathrm{O}, \mathrm{H})$ disynaptic basin representative of the $\mathrm{OH}$ bond. The profiles along the $\mathrm{O}(1) \mathrm{HO}(2)$ directions, represented in figure 7 enable a better understanding of the bonding differences between the crystal and the cluster. In the crystal $\mathrm{V}(\mathrm{H})$ is clearly separated from $\mathrm{V}(\mathrm{O} 1)$ on the left side, there is a minimum of the $E L F$ function at c. a. 0.89, the separation with the second $\mathrm{V}(\mathrm{O} 2)$ occurs at $E L F$ c. a. 0.41 . This profile is consistent with the very strong hydrogen bond picture is which the A-BH is already dissociated. The cluster calculation yields a very similar profile the separation of $\mathrm{V}(\mathrm{H})$ from $\mathrm{V}(\mathrm{O} 2)$ occurring at a slightly higher ELF value (0.49). Note that the $\mathrm{V}(\mathrm{H})$ population in the cluster is 0.36 and its variance 0.31 a value close to that of a $\left(\mathrm{PO}_{4} \mathrm{H}_{2}\right)^{-}$unit of the prototype dianion.
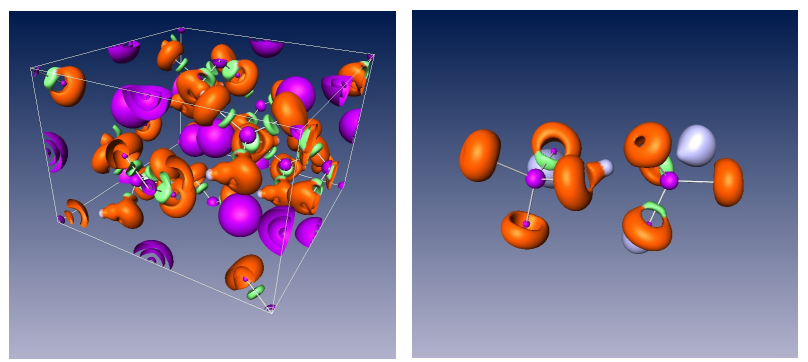

Fig. $6 \mathrm{ELF}=0.8$ localization domains of the KDP cell (left) and of the $\left[\mathrm{PO}_{4} \mathrm{H}_{2} \cdots \mathrm{PO}_{4} \mathrm{H}_{2}\right]^{2-}$ dianion. Color code as in figure 4 .
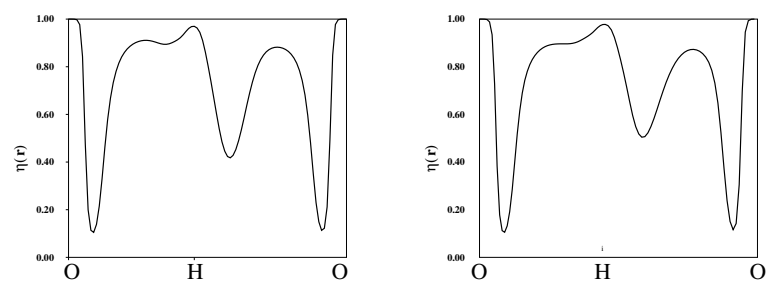

Fig. 7 ELF profiles along the $\mathrm{O}-\mathrm{H}$-..O. Left KDP: crystal, right: $\left[\mathrm{PO}_{4} \mathrm{H}_{2} \cdots \mathrm{PO}_{4} \mathrm{H}_{2}\right]^{2-}$ dianion model cluster.

\subsubsection{ICE VIII}

Ice VIII is the modification of ice stable in the pressure range $2-60 \mathrm{GPa}$ at low temperature. It has a tetragonal structure with space group $I 4_{1} / a m d$. The intramolecular
$\mathrm{OH}$ distance, $97.2 \mathrm{pm}$ at $2.7 \mathrm{GPa}$ is consistent with a weak or medium hydrogen bond in agreement with the energy barrier of the symmetric double-minimum potential calculated of the order of $10000 \mathrm{~cm}^{-157}$. The left side of figure 8 shows the $E L F=0.85$ localization domains of ice VIII whereas the right part displays the same domains of the water dimer. The two pictures are very similar, except for the size of the $\mathrm{V}(\mathrm{O}, \mathrm{H})$ domains of the dimer which are not involved in a hydrogen bond. The $E L F$ profiles along the $\mathrm{O}-\mathrm{H} \cdots \mathrm{O}$ bond line, presented in figure 9 are consistent with a weak hydrogen bond since the calculated CVB indexes are 0.03 in ice VIII, 0.008 in $\left(\mathrm{H}_{2} \mathrm{O}\right)_{2}$ and 0.012 in $\left(\mathrm{H}_{2} \mathrm{O}\right)_{5}$. The variance of the population of a $\mathrm{H}_{2} \mathrm{O}$ moiety is 0.08 in the dimer and 0.33 for the central molecule of the pentamer which forms two hydrogen bonds as proton donor and two others as proton acceptor. This result was anticipated by eq. 11 which suggest that the variance of a molecular moiety involved in several hydrogen bonds is an additive property.
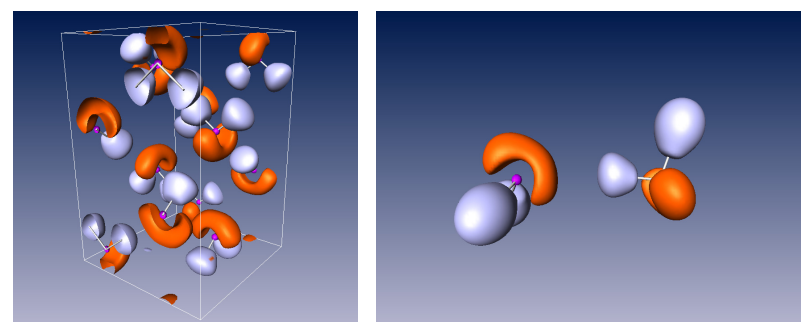

Fig. $8 E L F=0.85$ localization domains of the ice VIII cell(left) and water dimer (right). Color code as in figure 4.
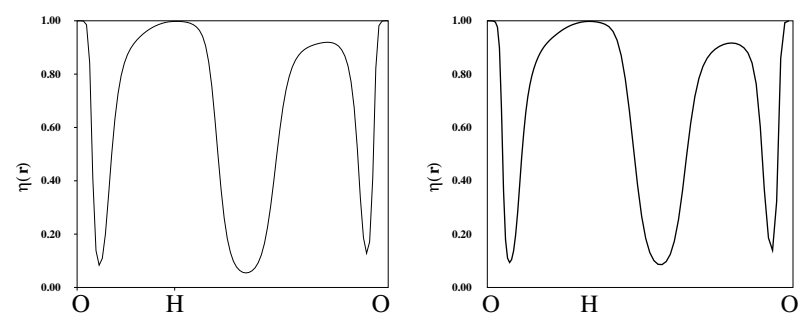

Fig. 9 ELF profiles along the $\mathrm{O}-\mathrm{H} \cdots \mathrm{O}$. Left: ice VIII crystal, right: water dimer.

In ice VIII, the $v_{\mathrm{OH}}$ frequency noticeably decreases ${ }^{62-64}$ whereas the $\mathrm{O}-\mathrm{H}$ bond length remains almost constant over the 2.7-9.0 GPa pressure range ${ }^{57,65}$. This behaviour of the stretching frequency is unexpected since stretching red-shifts are usually correlated with bond lengthening. This phenomenon is explained by the lowering under pressure of the energy barrier of the potential ${ }^{57}$ and is accounted for by a simple model taking the crystal field into 
account $^{66}$. Here we propose a chemical interpretation in terms of delocalization. The left part of figure 10 reports the $E L F$ value at the hydrogen bond interaction point for pressures ranging from 0 to $40 \mathrm{Gpa}$. This value linearly increases with pressure and therefore we expect from eq. 10 that the variance will increase as the square root of the pressure. At a pressure larger than $60 \mathrm{GPa}$ ice VIII undergoes a phase transition yielding a cubic structure, ice $X^{67-71}$. In ice $X$, the oxygen atoms are tetrahedrally coordinated to hydrogen atoms located exactly midway between two neighbouring oxygen atoms. This structure implies a single-minimum potential and therefore very strong hydrogen bonding. In the left part of figure 10 the light blue domains correspond to monosynaptic $\mathrm{V}(\mathrm{H})$ basins. Moreover, Marqués et al. have published the profile of the $E L F$ function along the $\mathrm{O}-\mathrm{H}-\mathrm{O}$ line ${ }^{72}$ which is very similar to that of $\mathrm{F}-\mathrm{H}-\mathrm{F}^{-}$of figure 5 .
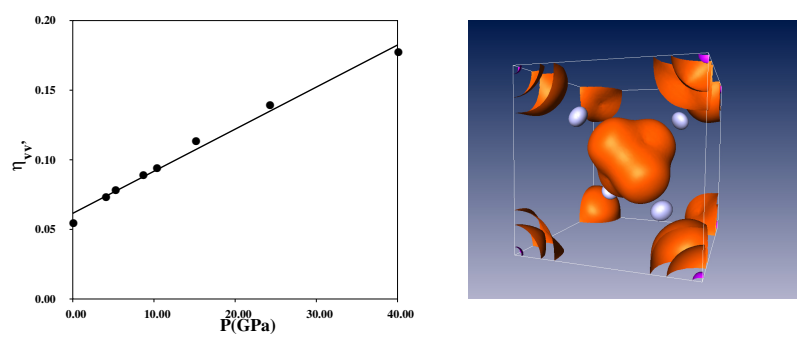

Fig. 10 Left: $E L F$ value at the hydrogen bond interaction point, $\eta_{v v^{\prime}}$ vs. pressure $(\mathrm{GPa})$ in ice VIII. Right: $E L F=0.85$ localization domains of the ice $\mathrm{X}$ cell. Color code as in figure 4.

\section{Conclusion: on the nature of the hydrogen} bond in molecular complexes and solids.

The hydrogen bonding is the most important type of molecular interactions and plays important role in chemistry, supramolecular systems, molecular biology and physics ${ }^{73,74}$. Every year more than 10000 research publications appear in the field of hydrogen bond. However, still the nature of the hydrogen bonding and definition of this interaction is controversial. In fact, the formation of the hydrogen bond can be understood from different point of views:

1. The intermolecular forces view point in which the interaction energy contributions are calculated from the electrostatic properties and polarizabilities of the unperturbed proton donor and proton acceptor moieties ${ }^{75-78}$. The approach is grounded on the Rayleigh Schrödinger perturbation scheme, it implies the conservation of the number of electrons in each subsystem and yields a decomposition of the interaction energy in terms of electrostatic, induction and dispersion contributions.

2. The orbital based decompositions ${ }^{79-84}$ which implicitly considers overlapping moieties. The interaction energy contributions are not related to an "exact wave function" but to the "approximate wave function".

3. The non-overlapping space filling decomposition which can be carried out on the basis of different criteria. Within the QTAIM approach ${ }^{26}$ the moieties are the unions of their constitutive atoms in molecule. As a consequence the integrated density over each moiety subspace is not an integral number. In this context it is possible to define a charge transfer. Moreover, each subsystems fulfils a local virial theorem. An analysis of the interaction energy in terms of the QTAIM fragments is possible. In the $E L F$ decomposition, the partition criterion is the minimization of the variance of the moiety populations. It is not possible to carry out an energy decomposition because the bounding surface of the moieties are not zero-flux surfaces of the density which forbid the evaluation of the kinetic energies of each subsystem. The discussion of the $\mathrm{H}$ bond is made on the basis of the variance which is the measure of the delocalization.

The choice of the ELF partition scheme for the study of delocalization in hydrogen bonded systems follows a simplicity principle (Occam's razor). Belonging to the non-overlapping class of partition scheme this procedure provides a well defined definition of the delocalization, the variance of the population which represents the spread of the electron count in a given chemically significant region of space. Moreover, it ensures that the calculated variance is minimal. The CVB index has been acknowledged to be a valuable indicator of the hydrogen bond strength since linear correlations depending on the nature of both acceptor and donor atoms have been obtained between the CVB index, proton donor stretching frequency shifts ${ }^{40}$ complexation energies and geometrical parameters. ${ }^{41}$. These correlations were difficult to interpret and in fact no explanation has been proposed so far. In the present study, eqns. 9 and 10 show that $I_{C V B}$ is a simple function of the variance. Therefore, quadratic instead of linear correlations between the variance of the population of the proton donor moiety and the frequency shifts, complexation energies and geometries can be expected expressing the dependence of these quantities upon delocalization. In our approach, it is expressed by a quantity, 
the contribution of individual hydrogen bonds to the variance of the proton donor/acceptor population, which is additive.

Recently, Weinhold and Klein, on the basis of NBO analysis of modern wave functions ${ }^{11,22}$ concluded that the electron density delocalization along the hydrogen bridge is a dominant contribution to the "nature" of the hydrogen bond. This proposal is supported by the delocalization analysis of the present study.

\section{References}

1 T. S. Moore and T. F. Winmill, J. Chem. Soc., 1912, 101, 1635-1676.

2 W. M. Latimer and W. H. Rodebush, J. Am. Chem. Soc., 1920, 42, 1419-1433.

3 Y. Marechal, The Hydrogen Bond and the Water Molecule: The Physics and Chemistry of Water, Aqueous and Bio-Media, Elsevier, Amsterdam, 2007.

4 G. Gilli and P. Gilli, The Nature of the Hydrogen Bond, Oxford University Press, Oxford, 2009.

5 S. J. Grabowski, Chem. Rev., 2011, 111, 2597-2625.

6 M. E. Alikhani, F. Fuster and B. Silvi, Structural Chemistry, 2005, 16, 203-210.

7 F. Fuster and B. Silvi, Chem. Phys., 2000, 252, 279287.

8 F. Weinhold and C. R.Landis, Valency and Bonding. A Natural Orbital Donor - Acceptor Perpepective, Cambridge University Press, New York, 2005.

9 R. Parthasarathi and V. Subramanian, Hydrogen Bonding -New Insights, New York, 2006, pp. 1-50.

10 S. Scheiner, Hydrogen Bonding. A Theoretical Perspective, Oxford University Press, New York, 1997.

11 F. Weinhold and R. A. Klein, Chem. Educ. Res. Pract., 2014, 15, 276-285.

12 G. C. Pimentel and A. L. MacClellan, The hydrogen bond, Reinhold, San Francisco, 1960.

13 J. Malecki, Molecular Interactions, New York, 1982, p. $183-240$.

14 S. N. Vinogradov and R. H. Linell, Hydrogen Bonding, Van Norstrand Reinhold Company, New York, 1971.

15 A. J. Barnes and Z. Mielke, J. Mol. Struct., 2012, $1023,216-223$.

16 G. S. Denisov, S. F. Bureiko, N. S. Golubov and K. G. Tokhadze, Molecular Interactions, New York, 1981, pp. $107-177$.

17 B. Silvi and A. Savin, Nature, 1994, 371, 683-686.

18 A. D. Becke and K. E. Edgecombe, J. Chem. Phys., 1990, 92, 5397-5403.
19 A. C. Legon and D. J. Millen, Discuss. Faraday Soc., 1982, 73, 71-87.

20 A. C. Legon and D. J. Millen, Chem. Soc. Rev., 1987, $16,467-498$.

21 F. O. Rice and E. Teller, J. Chem. Phys., 1938, 6, 489-496.

22 F. Weinhold and R. A. Klein, Molec. Phys., 2012, 110, 565-579.

23 S. Diner and P. Claverie, Localization and Delocalization in Quantum Chemistry, Reidel, Dordrecht, 1976, vol. II, pp. 395-448.

24 B. Silvi, Phys. Chem. Chem. Phys., 2004, 6, 256-260.

25 J. G. Ángyán, M. Loos and I. Mayer, J. Phys. Chem., 1994, 98, 5244-5248.

26 R. F. W. Bader, Atoms in Molecules: A Quantum Theory, Oxford Univ. Press, Oxford, 1990.

27 B. Silvi, I. Fourré and E. Alikhani, Monatshefte für Chemie, 2005, 136, 855-879.

28 R. F. W. Bader and P. M. Beddall, J. Chem. Phys., 1972, 56, 3320-3329.

29 P. W. Ayers, J. Chem. Sci., 2005, 117, 441-454.

30 B. Silvi, The Chemical Bond - 100 years old and getting stronger., Springer Berlin Heidelberg, Berlin, Heidelberg, 2016, pp. 213-248.

31 B. Silvi, M. Esmail Alikhani, C. Lepetit and R. Chauvin, Applications of Topological Methods in Molecular Chemistry, Springer International Publishing, Cham, 2016, pp. 1-20.

32 M. J. Frisch, G. W. Trucks, H. B. Schlegel, , G. E. Scuseria, M. A. Robb, J. R. Cheeseman, J. A. Montgomery, Jr., T. Vreven, K. N. Kudin, J. C. Burant, J. M. Millam, S. S. Iyengar, J. Tomasi, V. Barone, B. Mennucci, M. Cossi, G. Scalmani, N. Rega, G. A. Petersson, H. Nakatsuji, M. Hada, M. Ehara, K. Toyota, R. Fukuda, J. Hasegawa, M. Ishida, T. Nakajima, Y. Honda, O. Kitao, H. Nakai, M. Klene, X. Li, J. E. Knox, H. P. Hratchian, J. B. Cross, C. Adamo, J. Jaramillo, R. Gomperts, R. E. Stratmann, O. Yazyev, A. J. Austin, R. Cammi, C. Pomelli, J. W. Ochterski, P. Y. Ayala, K. Morokuma, G. A. Voth, P. Salvador, J. J. Dannenberg, V. G. Zakrzewski, S. Dapprich, A. D. Daniels, M. C. Strain, O. Farkas, D. K. Malick, A. D. Rabuck, K. Raghavachari, J. B. Foresman, J. V. Ortiz, Q. Cui, A. G. Baboul, S. Clifford, J. Cioslowski, B. B. Stefanov, A. L. G. Liu, P. Piskorz, I. Komaromi, R. L. Martin, D. J. Fox, T. Keith, M. A. Al-Laham, C. Y. Peng, A. Nanayakkara, M. Challacombe, P. M. W. Gill, B. Johnson, W. Chen, M. W. Wong, C. Gonzalez, and J. A. Pople, Gaussian 03, Revision A.1, Gaussian, Inc., Wallingford, CT, 2003. 
33 A. D. Becke, J. Chem. Phys., 1993, 98, 5648-5652.

34 C. Lee, Y. Yang and R. G. Parr, Phys. Rev., 1988, B37, 785 .

35 R. Krishnan, J. S. Binkley, R. Seeger and J. A. Pople, J. Chem. Phys., 1980, 72, 650-654.

36 T. Clark, J. Chandrasekhar, G. W. Spitznagel and P. von Ragué Schleyer, J. Comput. Chem., 1983, 4, 294.

37 M. J. Frisch, J. A. Pople and J. S. Binkley, J. Chem. Phys., 1984, 80, 3265-3269.

38 S. Noury, X. Krokidis, F. Fuster and B. Silvi, Comput. in Chem., 1999, 23, 597-604.

39 E. Cancès, R. Keriven, F. Lodier and A. Savin, Theor. Chem. Acc., 2004, 111, 373-380.

40 F. Fuster and B. Silvi, Theoret. Chem. Acc., 2000, 104, 13-21.

41 S. Gutierrez-Oliva, L. Joubert, C. Adamo, F. Bulat, J. Zagal and A. Toro-Labbe, J. Phys. Chem. A, 2006, 110, 5102-5107.

42 J. Contreras-García and J. M. Recio, Theor. Chem. Acc., 2011, 128, 411-418.

43 V. Tsirelson and A. Stash, Chem. Phys. Lett., 2002, $351,142-148$.

44 V. R. Saunders, R. Dovesi, C. Roetti, M. Causà, N. M. Harrison, R. Orlando and C. M. Zicovitch-Wilson, CRYSTAL98, User's manual, Torino, Italy, 1998.

45 C. Gatti, Topond98 manual, CNR-CSRSRC, Milano, Italy, 1998.

46 Amira 3.0, TGS, Template Graphics Sofware, Inc., San Diego, USA, 2002.

47 R. Dovesi, C. Roetti, C. Freyria-Fava, M. Prencipe and V. Saunders, Chem. Phys., 1991, 156, $11-19$.

48 B. Civalleri, A. M. Ferrari, M. Llunell, R. Orlando, M. Merawa and P. Ugliengo, Chemistry of Materials, 2003, 15, 3996-4004.

49 C. M. Zicovich-Wilson, A. Bert, C. Roetti, R. Dovesi and V. R. Saunders, J. Chem. Phys., 2002, 116, 11201127.

50 M. D. Towler, N. L. Allan, N. M. Harrison, V. R. Saunders, W. C. Mackrodt and E. Aprà, Phys. Rev. B, 1994, 50, 5041-5054.

51 R. Dovesi, C. Ermondi, E. Ferrero, C. Pisani and C. Roetti, Phys. Rev. B, 1984, 29, 3591-3600.

52 R. Nada, C. R. A. Catlow, C. Pisani and R. Orlando, Modelling and Simulation in Materials Science and Engineering, 1993, 1, 165.

53 W. J. Hehre, R. Ditchfield and J. A. Pople, J. Chem. Phys., 1972, 56, 2257-2261.

54 B. Silvi, Z. Latajka and H. Ratajczak, Ferroelectrics, 1993, 150, 303-311.
55 Z. Tun, R. J. Nelmes, W. F. Kuhs and R. F. D. Stansfield, Journal of Physics C: Solid State Physics, 1988, $21,245$.

56 J. A. Ibers, J. Chem. Phys., 1964, 40, 402-404.

57 J. M. Besson, P. Pruzan, S. Klotz, G. Hamel, B. Silvi, R. J. Nelmes, J. S. Loveday, R. M. Wilson and S. Hull, Phys. Rev. B, 1994, 49, 12540-12550.

58 X. Krokidis, V. Goncalves, A. Savin and B. Silvi, J. Phys. Chem. A, 1998, 102, 5065-5073.

59 X. Krokidis, R. Vuilleumier, D. Borgis and B. Silvi, Molec. Phys., 1999, 96, 265-273.

60 M. E. Alikhani and B. Silvi, J. Mol.Struct., 2004, 706, 3-6.

61 J. Emsley, Chem. Soc. Rev., 1980, 9, 91-124.

62 K. R. Hirsch and W. B. Holzapfel, J. Chem. Phys., 1986, 84, 2771-2775.

63 P. Pruzan, J. C. Chervin and B. Canny, J. Chem. Phys., 1993, 99, 9842-9846.

64 Y. Yoshimura, S. T. Stewart, M. Somayazulu, H.-k. Mao and R. J. Hemley, J. Chem. Phys., 2006, 124,.

65 R. J. Nelmes, J. S. Loveday, R. M. Wilson, J. M. Besson, P. Pruzan, S. Klotz, G. Hamel and S. Hull, Phys. Rev. Lett., 1993, 71, 1192.

66 B. Silvi, Phys. Rev. Lett., 1994, 73, 842-845.

67 W. B. Holzapfel, J. Chem. Phys., 1972, 56, 712-715.

68 A. F. Goncharov, V. V. Struzhkin, M. S. Somayazulu, R. J. Hemley and H. K. Mao, Science, 1996, 273, 218 220.

69 P. Loubeyre1, R. le Toullec, E. Wolanin, M. Hanfland and D. Hausermann, Nature, 1999, 397, 503-506.

70 M. Song, H. Yamawaki, H. Fujihisa, M. Sakashita and K. Aoki, Phys. Rev. B, 1999, 60, 12644-12650.

71 E. Sugimura, T. Iitaka, K. Hirose, K. Kawamura, N. Sata and Y. Ohishi, Phys. Rev. B, 2008, 77, 214103.

72 M. Marqués, G. J. Ackland and J. S. Loveday, High Pressure Research, 2009, 29, 208-211.

73 J.-M. Lehn, Angewandte Chemie International Edition, 2013, 52, 2836-2850.

74 J.-M. Lehn, Angewandte Chemie International Edition, 2015, 54, 3276-3289.

75 A. D. Buckingham and P. W. Fowler, J. Chem. Phys., 1983, 79, 6425-6428.

76 A. D. Buckingham, P. W. Fowler and A. J. Stone, Int. Rev. Phys. Chem., 1986, 5, 107-114.

77 A. D. Buckingham, P. W. Fowler and J. M. Huston, Chem. Rev., 1988, 88, 963-988.

78 A. D. Buckingham, Theoretical Treatments of Hydrogen Bonding, John Wiley and sons, Chichester, 1997, ch. 2, pp. 1-12. 
79 K. Kitaura and K. Morokuma, Int. J. Quant. Chem., 1976, vol. X, 325-340.

80 K. Morokuma and K. Kitaura, Molecular Interactions, Wiley ans sons, Chichester, 1980, vol. I, pp. 21-66.

81 K. Salewicz and B. Jeziorski, Molec. Phys., 1979, 38, 191.

82 B. Jeziorski and W. Kołos, Molecular Interactions, Wiley, New York, 1982, vol. III, pp. 1-46.

83 G. Chałasiński and M. M. Szczęśniak, Chem. Rev., 2000, 100, 4227-4252.

84 J. Hoja, A. F. Sax and K. Szalewicz, Chem. Eur. J., 2014, 20, 2292-2300. 